\title{
Mass Spectrometric Analysis Reveals Remnants of Host-Pathogen Molecular Interactions at the Starch Granule Surface in Wheat Endosperm
}

\author{
Michael L. Wall, Heather L. Wheeler, Jeffrey Smith, Daniel Figeys, and Illimar Altosaar
}

First, fourth, and fifth authors: Department of Biochemistry, Microbiology and Immunology, University of Ottawa, 451 Smyth Road, Ottawa, ON, KlH 8M5, Canada; second author: Department of Cell \& Systems Biology, University of Toronto, 25 Willcocks Street, Toronto, ON, M5S 3B2, Canada; third author: Department of Chemistry, Carleton University, 1125 Colonel By Drive, Ottawa, ON, K1S 5B6, Canada; and fourth and fifth authors: Ottawa Institute of Systems Biology, University of Ottawa, Canada. Accepted for publication 26 April 2010.

\begin{abstract}
Wall, M. L., Wheeler, H. L., Smith, J., Figeys, D., and Altosaar, I. 2010. Mass spectrometric analysis reveals remnants of host-pathogen molecular interactions at the starch granule surface in wheat endosperm. Phytopathology 100:848-854.

The starch granules of wheat seed are solar energy-driven deposits of fixed carbon and, as such, present themselves as targets of pathogen attack. The seed's array of antimicrobial proteins, peptides, and small molecules comprises a molecular defense against penetrating pathogens. In turn, pathogens exhibit an arsenal of enzymes to facilitate the degradation of the host's endosperm. In this context, the starch granule surface is a relatively unexplored domain in which unique molecular barriers may be deployed to defend against and inhibit the late stages of infection. Therefore, it was compelling to explore the starch granule surface in mature wheat seed, which revealed evidence of host-pathogen molecular interactions that may have occurred during grain development. In this

study, starch granules from the soft wheat Triticum aestivum cv. AC Andrew and hard wheat T. turgidum durum were isolated and water washed 20 times, and their surface proteins were digested in situ with trypsin. The peptides liberated into the supernatant and the peptides remaining at the starch granule surface were separately examined. In this way, we demonstrated that the identified proteins have a strong affinity for the starch granule surface. Proteins with known antimicrobial activity were identified, as well as several proteins from the plant pathogens Agrobacterium tumefaciens, Pectobacterium carotovorum, Fusarium graminearum, Magnaporthe grisea, Xanthomonas axonopodis, and X. oryzae. Although most of these peptides corresponded to uncharacterized hypothetical proteins of fungal pathogens, several peptide fragments were identical to cytosolic and membrane proteins of specific microbial pathogens. During development and maturation, wheat seed appeared to have resisted infection and lysed the pathogens where, upon desiccation, the molecular evidence remained fixed at the starch granule surface.
\end{abstract}

Wheat, like all plants, captures energy from sunlight and converts it into vitreous amyloplast-derived starch granule deposits composed of amylose and amylopectin $(5,32)$. These granules can be transitory, as found in green tissues; but, importantly, starch granules are also synthesized in developing grain endosperm for long-term storage (5). Fungal and bacterial pathogens that attack the developing kernel have adapted to seeking and obtaining vital nutrition from the starchy endosperm, an energy-rich storage tissue meant to fuel germination of the cognate embryo $(28,35)$. There are constant metabolic interactions between environmental pathogens and the cereal host over the energy stored in the endosperm (8). Evolution by adaptation suggests that novel, localized defense mechanisms are always in various stages of development and are constantly refined to combat the ever-changing strategies of attacking pathogens. Host resistance includes organelle-specific innate defense mechanisms, and antimicrobial small molecules, peptides, and proteins at starch granule surfaces can be considered the final line of defense against the invading organisms (8). Therefore, the starch granule surface in mature wheat grain represents a subcellular compartment where one may observe not only the direct interactions of host molecular defense mechanisms but also the pathogen molecular attack mechanisms. Studying such host-pathogen/protein-

Corresponding author: I. Altosaar; E-mail address: altosaar@uottawa.ca

doi:10.1094/PHYTO-100-9-0848

(c) 2010 The American Phytopathological Society protein interactions along the "walls of the energy vault" may identify novel resistance mechanisms.

The infection success of cereal pathogens depends on many factors. For example, wheat heads are most susceptible to pathogen attack during anthesis $(3,24)$. Environmental factors are also important. Although temperature influences the rate and severity of disease caused by Fusarium spp. (4), moisture is the overriding factor determining successful infection by Fusarium spp. $(6,21)$.

The infection pattern of fungal pathogens of wheat seed usually begins with germination on the inner surfaces of the lemma and palea as well as on the ovary within 12 to $24 \mathrm{~h}(25,34)$. The fungus then forms a network of mycelia after $2 \mathrm{~h}$. Following this, the hyphae penetrate inter- and intracellularly, causing severe damage to the infected host tissues. This can be viewed using microscopy techniques (29). Using scanning electron microscopy, fungal hyphae have been observed within the seed coat as well as within the endosperm (15). Bacterial pathogens, such as Pectobacterium carotovorum (also known as Erwinia carotovora), rely on evasion of plant defense mechanisms and secretion of degradative enzymes to digest plant cell walls $(14,18)$.

In the last decade, mass spectrometry has enabled the disentanglement of proteins and factors involved in host response to pathogen infection (23). Paper et al. (27) used a comparative approach to identify proteins expressed by Fusarium graminearum during infection of whole wheat seed. An advantage of mass spectrometry over other popular techniques, such as microarray analysis that only measures mRNA transcript levels, is that mass 
spectrometry can obtain information on extracellular and organellar protein localization. In addition, unlike microarray analysis, mass spectrometry deals with proteins directly, which is critical in that they are the primary determinants of phenotype.

Mass spectroscopic analysis of wheat amyloplasts revealed a high percentage of proteins involved in both storage and metabolism $(1,2)$. This is also true of proteomic studies in barley (11). Considering what is known about pathogen infection of wheat kernels, this area of research as it pertains to the starch granule surface proteome remains largely unexplored (17). Therefore, the present study aimed to use a proteomics approach to identify proteins tightly associated with the starch granule surface.

\section{MATERIALS AND METHODS}

Wheat samples. Mature seed of two model genotypes (33) were chosen for this study, one durum with no puroindoline and the other a soft wheat with wild-type PIN alleles. Triticum turgidum durum and T. aestivum cv. AC Andrew were obtained from the Eastern Cereal and Oilseed Research Centre (Agriculture and Agri-Food Canada, Ottawa, Canada), summer harvest year 2006. Both seed lots were from regular bulk plots on the same field with no fungicide treatment. Reagents were purchased from SigmaAldrich (St. Louis) unless otherwise noted. The preparation of wheat starch granules for mass spectrometric analysis was performed in triplicate.

Starch granule extraction. Wheat seed samples were sterilized in $0.25 \%$ sodium hypochlorite (4\% domestic bleach solution) for $10 \mathrm{~min}$, rinsed with distilled water 20 to 30 times, and dried overnight in a laminar flowhood. Seed were ground into a meal using a separate, clean mortar and pestle for each wheat species. The following procedure was performed in triplicate for each wheat sample: an aliquot of meal $(2 \mathrm{~g})$ was mixed with distilled water to form a dough ball. Distilled water was passed through the dough ball and, by gently squeezing the dough ball, a starch-granule-rich flow-through was obtained. To collect the granules, this flow-through was centrifuged at $1,600 \times g$ for $2 \mathrm{~min}$; the supernatant was discarded and the starch pellet was resuspended in distilled water. The resuspension and centrifugation wash step was repeated 20 times for each wheat sample.

Sampling the starch granule surface proteome. For "tryptic shaving," aliquots of water-washed starch granules ( $\approx 150 \mathrm{mg}$ ) were subjected to enzymatic shaving with trypsin (Promega Corp., Madison, WI) (5 $\mu \mathrm{g}$ of trypsin in $50 \mathrm{mM}$ sodium bicarbonate, $37^{\circ} \mathrm{C}$ overnight). Trypsin-treated granules were centrifuged $(18,000 \times g, 1 \mathrm{~min})$ and the aqueous supernatant was transferred to a fresh tube. The insoluble starch pellet was washed three times in distilled water. Peptides remaining on the insoluble granules were extracted by suspending the granules in $12 \mu \mathrm{l}$ of $50 \%$ isopropanol ( $\mathrm{vol} / \mathrm{vol}), 50 \mathrm{mM} \mathrm{NaCl}$ per milligram of wet weight. The granule suspensions were mixed at room temperature for $45 \mathrm{~min}$ and centrifuged at $2,500 \times g$ for $5 \mathrm{~min}$ to obtain the isopropanol supernatant. Insoluble pellets were discarded. The aqueous and isopropanol supernatants were both dried in a speedvac at $30^{\circ} \mathrm{C}$ for $4 \mathrm{~h}$ (Speed Vac Concentrator model number SVC100H; Savant Instruments, Inc. Hicksville, NY) Peptide pellets were resuspended in $40 \mu \mathrm{l}$ of distilled water, purified using ZipTips (Millipore, Bedford, MA) to remove salt and residual starch, and dried again in a speedvac $\left(30^{\circ} \mathrm{C}, 1 \mathrm{~h}\right)$. Peptides were resuspended in $40 \mu \mathrm{l}$ of $0.1 \%$ formic acid, separated by high-performance liquid chromatography (HPLC), and analyzed by electrospray ionization mass spectrometry, as detailed below.

Chromatography and mass spectrometry. Peptides were injected onto a 7 -cm by $200-\mu \mathrm{m}$ inner diameter trap column, fritted, and packed in-house with $5 \mathrm{~cm}$ of $5 \mu \mathrm{m}$ YMC ODS A reversed- phase packing material (Waters, Milford, MA) and separated using an Agilent 1100 HPLC (Agilent, Santa Clara, CA). The peptides were washed for $4 \mathrm{~min}$ at $20 \mu \mathrm{l} / \mathrm{min}$ with an aqueous solution containing $5 \%$ acetonitrile and $0.1 \%$ formic acid. The trap column was connected in series to a $6-\mathrm{cm}$ by $75-\mu \mathrm{m}$ Picofrit analytical column with a tip opening of $10 \mu \mathrm{m}$ (New Objective, Woburn, MA) and packed with $5 \mathrm{~cm}$ of YMC ODS A for mass spectrometric analysis as well as a diverter valve to split the solvent flow prior to the columns. Peptides were eluted from the trap and analytical columns at a flow rate of $\approx 250 \mathrm{nl} / \mathrm{min}$, ionized by nanoelectrospray ionization, and analyzed using a QSTAR Pulsar QqTOF mass spectrometer (Applied Biosystems, Foster City, CA) operating in information-dependent acquisition mode. Mass analysis included a 1-s survey scan followed by four 3-s tandem mass spectrometric scans on the most intense peaks in the spectrum; masses could be sequenced twice before being added to an exclusion list for $90 \mathrm{~s}$. The HPLC pumped $0.1 \%$ formic acid in water with the following percentage gradient of acetonitrile: $0 \mathrm{~min}, 5 \%$; $3 \mathrm{~min}, 15 \%$; $50 \mathrm{~min}, 40 \%$; $55 \mathrm{~min}, 50 \%$; and $60 \mathrm{~min}$, $80 \%$. Tandem mass spectrometric data were searched against a custom database consisting of all proteins from the comprehensive National Center for Biotechnology Information nonredundant (NCBInr) protein database using Mascot (Matrixscience Ltd., Boston). Mass tolerances were set to $\pm 100 \mathrm{ppm}$ and \pm 0.2 Da for the peptide and fragment ion spectra, respectively; up to two missed cleavages were considered. Oxidation of methionine residues was selected as a variable modification; no fixed modifications were selected because the tryptic shaving did not involve an alkylation step. Mass spectral significance was determined by searching the data against a "decoy" database containing a copy of the NCBInr database in reverse order and adjusting the ion score cutoff to $\geq 15$ such that the false-positive rate (proportional to the number of peptides matching to reversed sequences in the database) was $\leq 1 \%$ (12). Each match from the database was verified manually; data were deemed acceptable if at least three successive $y$ - or b-ions were present (or $y-++$ or $b-++$ ions if the charge state of the peptide was $>2+$ ).

\section{RESULTS}

Wheat starch granules from hard and soft wheat were isolated and water washed 20 times. Trypsin was added directly to the granule suspensions. The peptides liberated from the granule surfaces were collected as aqueous supernatants. To recover the peptide fragments remaining on the surface, the trypsin-treated starch granules were also extracted using 50\% isopropanol and $50 \mathrm{mM} \mathrm{NaCl}$, and these second supernatants were collected by centrifugation. All four peptide samples (aqueous supernatant and isopropanol supernatant for both the hard and soft wheat lines) were analyzed by mass spectrometry.

The results of the mass spectrometry analysis and Mascot protein identification are presented in five tables based on several criteria. Compiling fragment ion spectra from all four peptide samples (aqueous and isopropanol supernatants of hard and soft wheat starch granule peptides), Table 1 lists all peptides identical to regions of several known plant pathogen proteins, as annotated in the NCBI protein database.

To assess the nature of the starch granule surface proteome that may be either distantly tethered or, conversely, tightly bound, the peptides found in the two different supernatants are presented separately in Tables 2 and 3, respectively. Peptides in Table 2 are listed based upon two criteria: (i) those peptides found distal to the starch granule surface and, thus, released into the aqueous supernatant following tryptic digestion; and (ii) reported as being antimicrobial, as annotated in the NCBI protein database. Similar to Table 2, Table 3 lists peptides annotated by the NCBI protein database as antimicrobial in function but is restricted to peptides found proximal to the starch granule surface. Proximal peptides 
are defined as those peptides which remain bound to the starch granule surface following tryptic digestion and collected by extraction with $50 \%$ isopropanol and $50 \mathrm{mM} \mathrm{NaCl}$.

To highlight the fact that there were, from all four samples, peptides identical to regions of hypothetical or uncharacterized proteins, or proteins of unknown function, we have compiled these peptides into Table 4. Finally, peptides from all four samples identical to regions of plant proteins which are not antimicrobial are listed in Table 5.

The proteome of the starch granule surface. Several peptides identical to regions of proteins from common plant pathogens were identified on the surfaces of starch granules (Table 1). The species to which peptide identifications were made include $F$. graminearum, P. carotovorum, Xanthomonas oryzae, Agrobacterium tumefaciens, Magnaporthe grisea, and X. axonopodis. The hard wheat contained peptides identical to regions of proteins from all of the above-mentioned microbial species, whereas the soft wheat contained peptides identical to regions of proteins of only one plant pathogen, $X$. axonopodis. The majority of the proteins listed in Table 1 are hypothetical proteins derived from genomic open reading frame (ORF) sequences in the NCBI nucleotide database. However, several proteins listed in Table 1

TABLE 1. List of peptides identical to regions of proteins from the plant pathogens Agrobacterium tumefaciens, Fusarium graminearum, Pectobacterium carotovorum, Magnaporthe grisea, Xanthomonas axonopodis, and X. oryzae, generated from mass spectrometric analysis of aqueous supernatants and isopropanol extracts of trypsin-treated hard and soft wheat starch granules

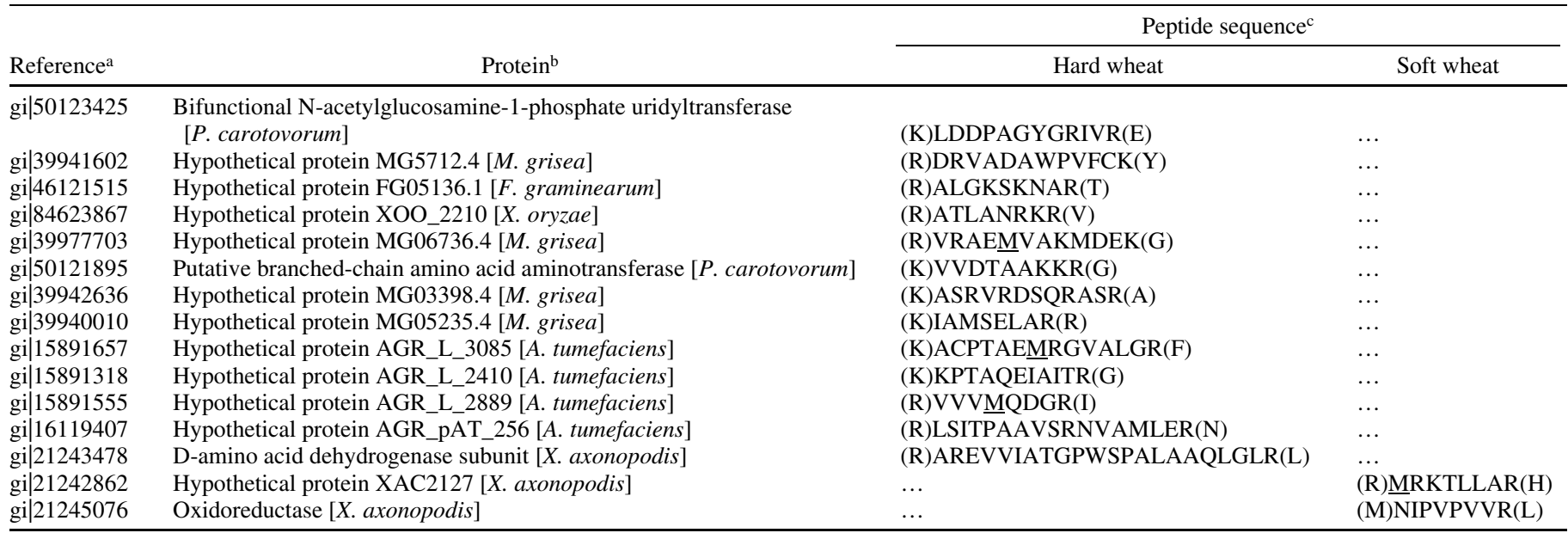

${ }^{a}$ GenBank GenInfo Identifier (gi) number for the most likely protein candidate for which peptides were identified.

${ }^{\mathrm{b}}$ Species from which each protein derives is indicated in square brackets.

${ }^{c}$ Where peptides were detected as having an oxidized methionine, the residues have been underlined. Amino acids in parentheses indicate residues expected to flank each identified peptide as determined from the corresponding protein's amino acid sequence.

TABLE 2. List of peptides identical to regions of known antimicrobial proteins, as annotated in the National Center for Biotechnology Information database, generated from mass spectrometric analysis of aqueous supernatants of trypsin-treated hard and soft wheat starch granules

\begin{tabular}{|c|c|c|c|}
\hline \multirow[b]{2}{*}{ Reference $^{\mathrm{a}}$} & \multirow[b]{2}{*}{ Protein $^{b}$} & \multicolumn{2}{|c|}{ Peptide sequence ${ }^{c}$} \\
\hline & & Hard wheat & Soft wheat \\
\hline \multirow[t]{5}{*}{ gi|391929 } & Tritin [Triticum aestivum] & (K)LTNVALGR(Q) & $\ldots$ \\
\hline & $\ldots$ & (K)TSPASTGLTLATR(A) & $\ldots$ \\
\hline & $\ldots$ & (R)FQTVSGFVAGVLEPK(E) & $\ldots$ \\
\hline & $\ldots$ & (K)AQVNGWQDLSEALLK(T) & $\ldots$ \\
\hline & $\ldots$ & (R)EAVTTLLLMVHEATR(F) & $\ldots$ \\
\hline \multirow[t]{2}{*}{ gi|5669008 } & Secretory protein [T. aestivum $]$ & (K)VLSDASAFIWK(T) & \\
\hline & $\ldots$ & (K)SGYTDDFFAQILGK(N) & (K)SGYTDDFFAQILGK(N) \\
\hline gi|62465514 & Class II chitinase [T. aestivum] & (R)AIGVDLLSNPDLVATDPTVSFK(T) & (R)AIGVDLLSNPDLVATDPTVSFK(T) \\
\hline \multirow[t]{2}{*}{$\mathrm{gi} \mid 22001285$} & $\begin{array}{l}\text { Peroxidase } 1[\text { T. aestivum }] \\
\ldots\end{array}$ & $\begin{array}{l}\text { (K)DIGLAAGLLR(L) } \\
\text { (R)DSVVVSGGPDYR(V) }\end{array}$ & $\begin{array}{l}\text { (K)DIGLAAGLLR(L) } \\
\ldots\end{array}$ \\
\hline & & (R)EGLFVSDQDLFTNDITRPIVER(F) & (R)EGLFVSDQDLFTNDITRPIVER(F) \\
\hline gi|132577 & $\begin{array}{l}\text { Protein synthesis inhibitor I (Ribosome- } \\
\text { inactivating protein I) [Hordeum vulgare] }\end{array}$ & (K)LTNVALGR(Q) & ( \\
\hline gi|20804336 & Xylanase inhibitor protein I [T. aestivum] & $\ldots$ & (R)ALATGIFER(A) \\
\hline gi| 116344 & $\begin{array}{l}\text { Endochitinase precursor (MF1 antigen) } \\
\text { [Brugia malayi] }\end{array}$ & 烈 & $(\mathrm{K}) \mathrm{SAQKTER}(\mathrm{F})$ \\
\hline gi|2894148 & Monomeric $\alpha$-amylase inhibitor [T. aestivum $]$ & $\ldots$ & (K)VPIPNPSGDR(A) \\
\hline gi|1709917 & Puroindoline-B precursor [T. aestivum] & $\cdots$ & (K)DFPVTWPTK(W) \\
\hline
\end{tabular}

${ }^{a}$ GenBank GenInfo Identifier (gi) number for the most likely protein candidate for which peptides were identified.

${ }^{\mathrm{b}}$ Species from which each protein derives is indicated in square brackets.

c Amino acids in parentheses indicate residues expected to flank each identified peptide as determined from the corresponding protein's amino acid sequence. $\mathrm{N}$-terminal peptides are indicated by $(-)$ at the $\mathrm{N}$-terminus. 
have been previously characterized and are known to localize to the cytosol, as annotated in the NCBI protein database. For example, one 14-mer peptide was identical to a region of a bifunctional $\mathrm{N}$-acetylglucosamine-1-phosphate uridyltransferase, an enzyme involved in bacterial cell wall synthesis (GenBank GenInfo Identifier no. gi|50123425).

Among the peptides identical to regions of plant proteins, several proteins belong to classes that have antimicrobial activity, as annotated in the NCBI protein database. These proteins are organized into Table 2 (aqueous supernatant distal peptides) and Table 3 (isopropanol supernatant proximal peptides). Seven unique antimicrobial proteins were identified in the aqueous supernatant of trypsin-treated hard wheat starch granules as op- posed to nine in the aqueous supernatant of trypsin-treated soft wheat starch granules (Table 2). Although most were identified by a single peptide, a few peptides corresponded to regions of the same protein. For example, 10 peptides, each identical to a region of the ribosome-inactivating protein tritin (gi|3912929), were found in both the aqueous supernatant (Table 2) and isopropanol supernatant (Table 3) of the hard wheat sample. From soft wheat, only one peptide of tritin was found in the aqueous supernatant whereas four peptides of tritin were found in the isopropanol supernatant.

From all four samples, several peptides were identical to regions of hypothetical plant proteins (genomic ORF DNA sequence only) or plant proteins of unknown function (protein

TABLE 3. List of peptides identical to regions of known wheat antimicrobial proteins, generated from mass spectrometric analysis of isopropanol extracts of trypsin-treated hard and soft wheat starch granules

\begin{tabular}{|c|c|c|c|}
\hline \multirow[b]{2}{*}{ Reference $^{\mathrm{a}}$} & \multirow[b]{2}{*}{ Protein $^{\mathrm{b}}$} & \multicolumn{2}{|l|}{ Peptide sequence $^{c}$} \\
\hline & & Hard wheat & Soft wheat \\
\hline \multirow[t]{5}{*}{ gi|391929 } & Tritin [Triticum aestivum] & (R)ADNLYWEGFK(S) & \\
\hline & $\ldots$ & (R)QQMADAVTALYGR(T) & (R)QQMADAVTALYGR(T) \\
\hline & $\ldots$ & (R)FQTVSGFVAGVLHPK(E) & \\
\hline & $\ldots$ & (K)AQVNGWQDLSEALLK(T) & (K)AQVNGWQDLSEALLK(T) \\
\hline & $\ldots$ & (R)EAVTTLLLMVHEATR(F) & \\
\hline \multirow[t]{2}{*}{ gi|5669008 } & Secretory protein $[$ T. aestivum $]$ & (K)VLSDASAFIWK(T) & \\
\hline & & (K)SGYTDDFFAQILGK(N) & (K)SGYTDDFFAQILGK(N) \\
\hline \multirow[t]{2}{*}{ gi|62465514 } & Class II chitinase [T. aestivum] & (R)AIGVDLLSNPDLVATDPTVSFK(T) & (R)GPIQLSHNYNYGPAGR(A) \\
\hline & & (R)AIGVDLLSNPDLVATDPTVSFK(T) & $\ldots$ \\
\hline gi|22001285 & Peroxidase $1[$ T. aestivum $]$ & (K)DIGLAAGLLR(L) & \\
\hline gi 20804336 & Xylanase inhibitor protein I [T. aestivum $]$ & $\ldots$ & (R)ALATGIFER(A) \\
\hline
\end{tabular}

${ }^{a}$ GenBank GenInfo Identifier (gi) number for the most likely protein candidate for which peptides were identified.

${ }^{\mathrm{b}}$ Species from which each protein derives is indicated in square brackets.

c Amino acids in parentheses indicate residues expected to flank each identified peptide as determined from the corresponding protein's amino acid sequence.

TABLE 4. List of peptides identical to regions of proteins identified by Mascot as being hypothetical or of unknown function, generated from mass spectrometric analysis of aqueous supernatants and isopropanol extracts of trypsin-treated hard and soft wheat starch granules

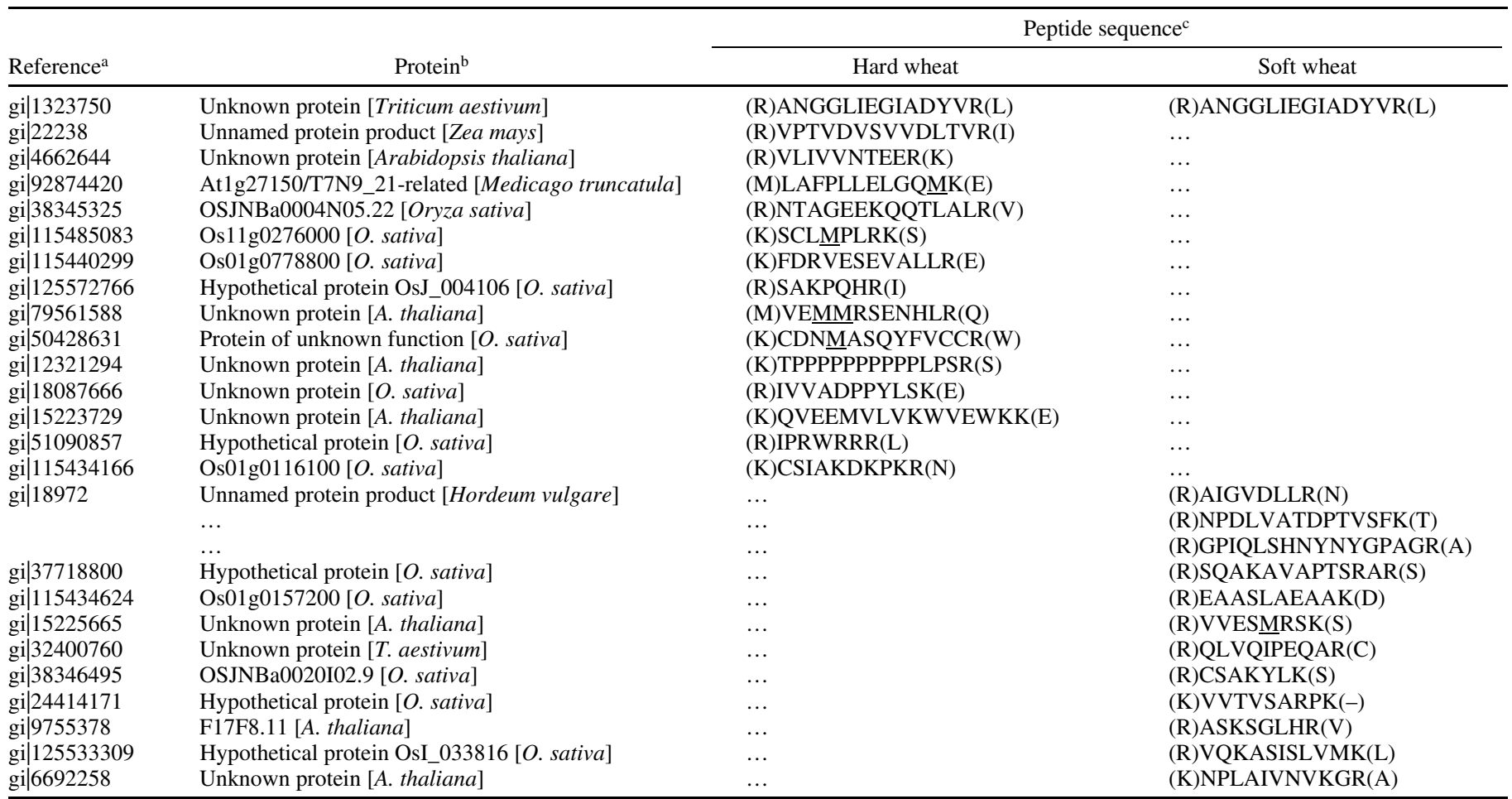

${ }^{a}$ GenBank GenInfo Identifier (gi) number for the most likely protein candidate for which peptides were identified.

${ }^{\mathrm{b}}$ Species from which each protein derives is indicated in square brackets.

${ }^{c}$ Amino acids in parentheses indicate residues expected to flank each identified peptide as determined from the corresponding protein's amino acid sequence.

$\mathrm{C}$-terminal peptides are indicated by $(-)$ at the $\mathrm{C}$-terminus. Where peptides were detected as having an oxidized methionine, the residues have been underlined. 
sequence only). These peptides have been compiled into Table 4 and represent a source of novel starch-granule-associated proteins.

Peptides from all four samples that were found to match regions of plant proteins are listed in Table 5. They compose a variety of protein classes, including starch granule synthesis (gi|4760582 starch synthase, GBSSI), storage (gi|228310 globulin 2 ), and transcription (gi|18401374 transcription factor). Proteins such as GBSSI and a grain softness protein (gi|607198) are

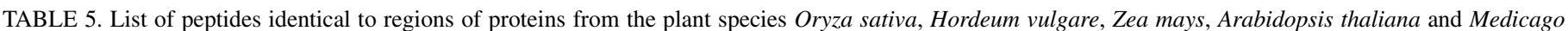
truncatula, generated from mass spectrometric analysis of aqueous supernatants and isopropanol extracts of trypsin-treated hard and soft wheat starch granules

\begin{tabular}{|c|c|c|c|}
\hline \multirow[b]{2}{*}{ Reference $^{\mathrm{a}}$} & \multirow[b]{2}{*}{ Protein $^{\mathrm{b}}$} & \multicolumn{2}{|c|}{ Peptide sequence ${ }^{c}$} \\
\hline & & Hard wheat & Soft wheat \\
\hline \multirow[t]{5}{*}{ gi|4760582 } & Starch synthase (GBSSI) [Triticum aestivum] & (K)DAWDTSVVSEIK(V) & $\ldots$ \\
\hline & $\ldots$ & (K)EALQAEVGLPVDR(K) & $\ldots$ \\
\hline & $\ldots$ & (K)FLAANYDVTTALEGK(A) & $\ldots$ \\
\hline & $\ldots$ & (K)SSFDFIDGYDKPVEGR(K) & $\ldots$ \\
\hline & $\ldots$ & (K)VLTVSPYYAEELISGEAR(G) & $\ldots$ \\
\hline \multirow[t]{3}{*}{ gi|32400764 } & $\beta$ Amylase $[$ T. aestivum $]$ & (R)YDPTAYNTILR(N) & $\ldots$ \\
\hline & $\ldots$ & (R)FFVDNGTYLTEQGR(F) & $\ldots$ \\
\hline & $\ldots$ & (K)AAAAMVGHPEWEFPR(D) & $\ldots$ \\
\hline \multirow[t]{2}{*}{ gi|169777 } & $\beta$ Amylase $[$ Oryza sativa $]$ & (K)SAPEELVQQVLSAGWR(E) & $\ldots$ \\
\hline & $\ldots$ & (R)NIEYLTLGVDDQPLFHGR(T) & $\ldots$ \\
\hline gi|1323750 & Unknown protein [T. aestivum] & (R)ANGGLIEGIADYVR(L) & (R)ANGGLIEGIADYVR(L) \\
\hline \multirow[t]{3}{*}{ gi|167004 } & Embryo globulin [Hordeum vulgare] & (R)VAIMEVNPR(A) & $\ldots$ \\
\hline & $\ldots$ & (R)VAIMEVNPR(A) & $\ldots$ \\
\hline & $\ldots$ & (R)DTFNLLEQRPK(I) & $\ldots$ \\
\hline gi| 228310 & Globulin 2 [Zea mays] & (K)EGEGVIVLLR(G) & (K)EGEGVIVLLR(G) \\
\hline gi| 17425168 & $\begin{array}{l}\text { Low-molecular-weight glutenin subunit group } 3 \text { type II } \\
\text { [T. aestivum }]\end{array}$ & (R)TTTRVPFGVGTGVGGY(-) & \\
\hline gi|15220239 & RNA binding protein [Arabidopsis thaliana] & (K)IVAILGSMRVPN(-) & $\begin{array}{l}\cdots \\
\ldots\end{array}$ \\
\hline gi| 15148385 & Gamma-gliadin [T. aestivum] & (K)APFASIVADIGGQ(-) & $\cdots$ \\
\hline gi| 607198 & $15-\mathrm{kDa}$ grain softness protein [T. aestivum] & (K)AIWTSIQGDLSGFK(G) & $\ldots$ \\
\hline gi| 22238 & Unnamed protein product $[$ Z. mays $]$ & (R)VPTVDVSVVDLTVR(I) & $\ldots$ \\
\hline gi| 15241221 & Structural molecule [A. thaliana] & (K)VLRSRSRR(L) & $\ldots$ \\
\hline gi|4662644 & Unknown protein $[$ A. thaliana $]$ & (R)VLIVVNTEER(K) & $\ldots$ \\
\hline gi| 12323783 & Putative exportin, tRNA [A. thaliana $]$ & (R)SKVTSFIHR(M) & $\ldots$ \\
\hline gi|92874420 & At1g27150/T7N9_21-related [Medicago truncatula] & (M)LAFPLLELGQMK(E) & $\ldots$ \\
\hline gi| 886965 & Low molecular weight glutenin $[T$. aestivum $]$ & (R)QLPQIPEQSR(Y) & $\ldots$ \\
\hline gi|38345325 & OSJNBa0004N05.22 [O. sativa] & (R)NTAGEEKQQTLALR(V) & $\ldots$ \\
\hline gi| 115485083 & Os11g0276000 [O. sativa] & (K)SCLMPLRK(S) & $\ldots$ \\
\hline gi| 115440299 & Os01g0778800 [O. sativa] & (K)FDRVESEVALLR(E) & $\ldots$ \\
\hline gi| 125572766 & Hypothetical protein OsJ_004106 [O. sativa] & (R)SAKPQHR(I) & $\ldots$ \\
\hline gi|79561588 & Unknown protein $[$ A. thaliana $]$ & (M)VEMMRSENHLR(Q) & $\ldots$ \\
\hline gi|50428631 & Protein of unknown function [O. sativa] & (K)CDNMASQYFVCCR(W) & $\ldots$ \\
\hline gi|12321294 & Unknown protein $[$ A. thaliana $]$ & (K)TPPPPPPPPPPLPSR(S) & $\ldots$ \\
\hline gi| 18401374 & Transcription factor $[$ A. thaliana $]$ & (K)TLWSRAILSKAVK(L) & $\ldots$ \\
\hline gi| 18087666 & Unknown protein $[O$. sativa $]$ & (R)IVVADPPYLSK(E) & $\ldots$ \\
\hline gi| 15223729 & Unknown protein $[$ A. thaliana $]$ & (K)QVEEMVLVKWVEWKK(E) & $\ldots$ \\
\hline gi|51090857 & Hypothetical protein [O. sativa] & (R)IPRWRRR(L) & $\ldots$ \\
\hline gi| 15232073 & Lyase/pectate lyase [A. thaliana] & (R)IYVVTSPR(D) & $\ldots$ \\
\hline gi| 115434166 & Os01g0116100 [O. sativa $]$ & (K)CSIAKDKPKR(N) & $\ldots$ \\
\hline gi| 75282488 & Protein $\mathrm{H} 2 \mathrm{~A} .5$ [T. aestivum] & (R)LLAGVTIAHGGVIPNINSVLLPK(K) & $\ldots$ \\
\hline gi| 871551 & Serpin (protease inhibitor) [T. aestivum] & (K)ISFGIEASDLLK(C) & $\ldots$ \\
\hline \multirow[t]{3}{*}{ gi| 18972} & Unnamed protein product $[H$. vulgare $]$ & $\ldots$ & (R)AIGVDLLR(N) \\
\hline & $\ldots$ & $\ldots$ & (R)NPDLVATDPTVSFK(T) \\
\hline & $\ldots$ & $\ldots$ & (R)GPIQLSHNYNYGPAGR(A) \\
\hline gi|37718800 & Hypothetical protein [O. sativa] & $\ldots$ & (R)SQAKAVAPTSRAR(S) \\
\hline gi| 92875830 & Trp repressor/replication initiator $[M$. truncatula $]$ & $\ldots$ & $(\mathrm{K}) \operatorname{VFSDEVIR}(\mathrm{F})$ \\
\hline gi|92893314 & $\begin{array}{l}\text { Ribonuclease } \mathrm{H} ; \text { Glutathione S-transferase, C-terminal-like } \\
{[\text { M. truncatula }]}\end{array}$ & $\ldots$ & (K)KIWSKDIPPSK(S) \\
\hline gi|115434624 & Os01g0157200 [O. sativa $]$ & $\ldots$ & (R)EAASLAEAAK(D) \\
\hline gi 15225665 & Unknown protein $[$ A. thaliana $]$ & $\ldots$ & (R)VVESMRSK(S) \\
\hline gi|32400760 & Unknown protein [T. aestivum] & $\ldots$ & (R)QLVQIPEQAR(C) \\
\hline gi|54291437 & Pr1-like protein $[O$. sativa $]$ & $\ldots$ & (R)RELESGKEEGR(R) \\
\hline \multirow[t]{2}{*}{ gi| 14587294} & Putative permease $1[O$. sativa] & $\ldots$ & (R)GMPWWVPFR(S) \\
\hline & $\ldots$ & $\ldots$ & (R)GMPWWVPFR(S) \\
\hline gi|38346495 & OSJNBa0020I02.9 [O. sativa] & $\ldots$ & (R)CSAKYLK(S) \\
\hline gi| 24414171 & Hypothetical protein $[O$. sativa $]$ & $\ldots$ & (K)VVTVSARPK(-) \\
\hline gi|9755378 & F17F8.11 $[$ A. thaliana $]$ & $\ldots$ & (R)ASKSGLHR(V) \\
\hline gi| 125533309 & Hypothetical protein OsI_033816 [O. sativa] & $\ldots$ & (R)VQKASISLVMK(L) \\
\hline gi|50726319 & $\begin{array}{l}\text { Putative BRCA1 interacting protein C-terminal helicase } 1 \\
{[\text { O. sativa }]}\end{array}$ & & $x^{2}$ \\
\hline gi|6692258 & Unknown protein $[$ A. thaliana $]$ & $\begin{array}{l}\cdots \\
\cdots\end{array}$ & (K)NPLAIVNVKGR(A) \\
\hline gi| 15229913 & CYP71B38; heme binding/iron ion binding/monooxygenase & & \\
\hline & /oxygen binding $[$ A. thaliana $]$ & & (K)KVPLVLIQTSHR(W) \\
\hline gi|30688003 & Phosphoinositide 5-phosphatase $[$ A. thaliana $]$ & $\ldots$ & (R)NFKLTLIAR(R) \\
\hline
\end{tabular}

a GenBank GenInfo Identifier (gi) number for the most likely protein candidate for which peptides were identified.

b Species from which each protein derives is indicated in square brackets.

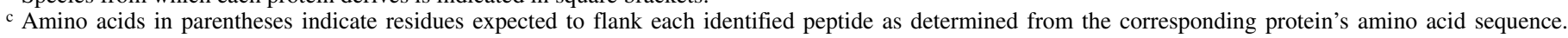
$\mathrm{C}$-terminal peptides are indicated by $(-)$ at the $\mathrm{C}$-terminus. Where peptides were detected as having an oxidized methionine, the residues have been underlined. 
known to be strongly associated with the starch granule surface $(9,10)$. Overall, more peptides were identified in the hard wheat $(52$ peptides) than the soft wheat samples (30 peptides). Finally, several peptides corresponded to proteins of related organisms with no homologous proteins sequenced in wheat as well as numerous peptides that have not been sequenced in any organism.

\section{DISCUSSION}

Proteins of pathogen origin. Peptides identical to regions of proteins of plant pathogens were identified at the starch granule surface (Table 1). More peptides (13 peptides from six pathogen species) were identified from hard wheat starch granules than from soft wheat starch granules (2 peptides from one pathogen species). It may be that fewer molecular "footprints" were left behind by pathogen intruders in soft wheat, implying that soft wheat has a more robust antimicrobial armament than hard wheat. Many factors may be at play in such a scenario; anatomical and biochemical characteristics may include differences in the waxy cuticle between hard and soft wheat grains, numbers of pericarp cell layers, suberization, and even enzyme inhibitors in the aleurone or subaleurone cell layers. Pathogen proteins closely associated with the starch granules of wheat may be the molecular remnants of a failed pathogen attack against the developing or mature granules of the wheat kernel. Using a green fluorescent protein-expressing Fusarium sp., Skadsen et al. (30) showed that the fungus was able to infect the majority of a wheat seed coat 16 days after inoculation, though no infection of the endosperm was observed using this method. However, microscopy of F. graminearum-infected wheat and barley endosperm have shown pitted starch granules and fungal hyphae $(15,26)$. Therefore, it is not surprising to find remnant proteins of fungal pathogens within the endosperm of mature wheat kernels. We propose that such molecular footprints of grain shipments may be used to trace the cumulative historical record of its incurred biotic stresses or pathogen load.

Of the pathogen proteins identified (Table 1), several are cytosolic and serve no known direct role in pathogenicity. These include an oxidoreductase (gi|21245076), a D-amino acid dehydrogenase subunit (gi|21243478), a putative branched-chain amino acid aminotransferase (gi|50121895), and a bifunctional Nacetylglucosamine-1-phosphate uridyltransferase (gi|50123425). This suggests that bacterial pathogens and fungal hyphae were lysed during seed maturation and fixed in place within the desiccated endosperm. The in planta role of these hypothetical plant pathogen proteins in Table 1 may be in some way associated with starch granule degradation or they may be related to the recognition and degradation of carbohydrate polymers in general. However, like the cytosolic pathogen proteins, the hypothetical proteins may not be directly involved in infection. Further study is needed to characterize and elucidate the function of these hypothetical proteins to determine the role they may play in hostpathogen interactions.

The presence of peptides identical to regions of plant pathogen proteins suggests that the tryptic shaving and mass spectrometric approach of probing the starch granule surface goes beyond providing insight into the starch granule proteome only: it provides a view of the "late-game" interaction between plant and pathogen. Further experiments may determine the effect of pathogen infection on the wheat starch granule proteome or, conversely, the effect of variation in the wheat starch granule proteome on pathogen infection.

Host defense proteins. Because defense-related proteins are known to compose an important fraction of the cereal proteome (19), we set out to discover proteins defending the seed's energy stores. Peptides identical to regions of several antimicrobial proteins, as annotated in the NCBI protein database, were identified in the supernatant and granule-bound isolates of tryptically shaved hard and soft wheat starch granules (Tables 2 and 3). If present at the starch granule surface, these proteins may play a role in protecting the starch granule from invading pathogens. This would ensure that the starch granules are preserved exclusively for the developing wheat embryo. Interestingly, a peptide identical to a region of an amylase inhibitor was identified in the supernatant (gi|2894148) (Table 2). $\alpha$-Amylase and other glycosylase inhibitors may play a role in preventing the breakdown of starch and cell wall components by invading pathogens or may play a role in regulating growth and degradation of the starch granule by the plant itself $(13,22)$. Another interesting result is the detection of a xylanase inhibitor (gi|20804336) (Tables 2 and 3), specifically a xylanase-inhibiting protein (XIP)-type inhibitor associated with the starch granules of soft wheat. A proteomic analysis of four commercial starches by Kasarda et al. (17) identified xylanase inhibitors, suggesting that they may play a role in antimicrobial activity. XIP is exclusively expressed in wheat endosperm and has been suggested to play a role in plant defense (7). Although XIP-type xylanase inhibitors are secreted into the intercellular matrix (16), it may be possible that, during seed maturation and desiccation, some of the highly expressed xylanase inhibitors become associated with the starch granule surface. It is important to note, when comparing these tables, that several peptides in Table 3 are identical to those in Table 2, indicating that there were some proteins found in both the aqueous and isopropanol extracts. Given that the latter is 50\% aqueous, it is not surprising that the two solvents were not mutually exclusive to a degree high enough as to effect a discriminatory or differential solubility of granule-bound proteins.

Hypothetical proteins. The proteome of any organism is highly diverse and the identification and characterization of most proteomes is largely incomplete. The motivation to characterize novel proteins generally depends on their candidacy for connection or interaction with a characterized system. By limiting our analysis to the starch granule proteome, novel identifications may be related to starch granule defense or metabolism, pending future experiments.

The use of mass spectrometric techniques to discover unknown and hypothetical proteins localized to specific organellar compartments, such as the starch granule surface, may aid in expanding the body of knowledge of host-pathogen interactions and, perhaps, result in the discovery of novel resistance mechanisms. For example, the unknown protein with gi|1323750 (Table 4) is the protein product of a cDNA sequence (gi|1323750). This cDNA sequence from wheat was entered into the database in 1996 and contains an ORF annotated as "unknown." Subsequently, this protein of unknown function was found to match the superfamily of basic secretory protein class of proteins thought to play a role in host defense (20). Other hypothetical proteins, such as OsJ_004106 (gi|125572766), did not match with any known proteins, nor do they contain any known conserved domains when analyzed using the NCBI BLAST protein search tools. Therefore, these hypothetical proteins can no longer be considered hypothetical because the present peptide extraction actually recovered them from granules as bona fide wheat proteins. This novel cohort of wheat proteins presents an opportunity to explore potentially new classes of antimicrobial or starch-metabolism-related proteins not yet characterized.

Host proteins related to storage and metabolism. Similar to other proteomic studies of wheat and potato amyloplasts $(1,2,31)$, a number of proteins related to defense (Tables 2 and 3) and starch granule metabolism and storage (Table 5) were identified in the present study. These include the starch metabolism enzymes granule-bound starch synthase I (GBSS I) and $\beta$-amylase, as well as the storage protein globulin, identified here as the barley protein, embryo globulin. The identification of proteins already known to associate with the starch granule, such as GBSS I and grain softness protein, validates the efficacy of this current tryptic shaving technique to probe the starch granule surface 
proteome and extend this organellar approach to the investigation of host-pathogen interactions. Peptides identical to regions of proteins from the cereals rice, barley, and corn as well as the model plants Arabidopsis and alfalfa were identified. For these protein hits, it is most likely that the reason they are annotated as non-wheat is that they share sequence identity with homologs from wheat which have not yet had DNA, RNA, or protein sequence information reported and, therefore, are annotated only under related organisms which have had their genomes sequenced. It is interesting to note that our Mascot identification did not proffer any host stress-related proteins. Other proteomic studies, such as that by Kasarda et al. (17), detected peptides identical to regions of stress-related proteins.

In conclusion, this tryptic peptide shaving of hard and soft wheat starch granules was a useful means to characterize hostpathogen interactions at the gateway to energy reserves. Isolating tightly bound peptides from the starch granule surface identified peptide sequences from six common field pathogens of wheat. Many other recovered peptides were unique in that they were the first occurrence of previous putative proteins indicated by genomic data. Recovering this novel community of both host and pathogen proteins clustered on the granule landscape now permits a more dynamic tracking of the penetrative power of pathogens and their proteins.

\section{ACKNOWLEDGMENTS}

M. L. Wall and H. L. Wheeler contributed equally to the work. We thank NSERC (Discovery grant, I. Altosaar; USRA, H. L. Wheeler) and CIHR (Operating grant, I. Altosaar) for funding, and the editor and reviewers whose critical review greatly improved this article. Dedicated to the memory of Jaan Sarv (1922 to 1991) who devoted his life to breeding resistance to Erwinia.

\section{LITERATURE CITED}

1. Andon, N. L., Hollingworth, S., Koller, A., Greenland, A. J., Yates, J. R., and Haynes, P. A. 2002. Proteomic characterization of wheat amyloplasts using identification of proteins by tandem mass spectrometry. Proteomics 2:1156-1168.

2. Balmer, Y., Vensel, W. H., DuPont, F. M., Buchanan, B. B., and Hurkman, W. J. 2006. Proteome of amyloplasts isolated from developing wheat endosperm presents evidence of broad metabolic capability. J. Exp. Bot. 57:1591-1602.

3. Bottalico, A., and Perrone, G. 2002. Toxigenic Fusarium species and mycotoxins associated with head blight in small-grain cereals in Europe. Eur. J. Plant Pathol. 108:611-24.

4. Brennan, J. M., Egan, D., Cooke, B. M., and Doohan, F. M. 2005. Effect of temperature on head blight of wheat caused by Fusarium culmorum and $F$. graminearum. Plant Pathol. 54:156-160.

5. Buleon, A., Colonna, P., Planchot, V., and Ball, S. 1998. Starch granules: structure and biosynthesis. Int. J. Biol. Macromol. 23:85-112.

6. Cowger, C., Patton-Ozkurt, J., Brown-Guedira, G., and Perugini, L. 2009. Post-anthesis moisture increased Fusarium head blight and deoxynivalenol levels in North Carolina winter wheat. Phytopathology 99:320-327.

7. Croes, E., Gebruers, K., Luyten, N., Delcour, J. A., and Courtin, C. M. 2009. The three classes of wheat xylanase-inhibiting proteins accumulate in an analogous way during wheat ear development and germination. J. Plant Physiol. 166:1253-1262.

8. Dangl, J. L., and Jones, J. D. G. 2001. Plant pathogens and integrated defence responses to infection. Nature 411:826-833.

9. Dubreil, L., Gaborit, T., Bouchet, B., Gallant, D. J., Broekaert, W. F., Quillien, L., and Marion, D. 1998. Spatial and temporal distribution of the major isoforms of puroindolines (puroindoline-a and puroindoline-b) and non specific lipid transfer protein (ns-LTPle(1)) of Triticum aestivum seeds. Relationships with their in vitro antifungal properties. Plant Sci. 138:121-135.

10. Feiz, L., Wanjugi, H. W., Melnyk, C. W., Altosaar, I., Martin, J. M., and Giroux, M. J. 2009. Puroindolines co-localize to the starch granule surface and increase seed bound polar lipid content. J. Cereal Sci. 50:91-98.

11. Finnie, C., Melchior, S., Roepstorff, P., and Svensson, B. 2002. Proteome analysis of grain filling and seed maturation in barley. Plant Physiol. 129:1308-1319.

12. Higdon, R., Hogan, J. M., Van Belle, G., and Kolker, E. 2005.
Randomized sequence databases for tandem mass spectrometry peptide and protein identification. Omics 9:364-79.

13. Howell, J. T., and Davis, M. R. 2005. Plant defense mechanisms against fungal pathogens: Polygalacturonase inhibitor proteins. Can. J. Plant Pathol. 24:5-15.

14. Hugouvieux-Cotte-Pattat, N., Condemine, G., Nasser, W., and Reverchon, S. 1996. Regulation of pectinolysis in Erwinia chrysanthemi. Annu. Rev. Microbiol. 50:213-257.

15. Jackowiak, H., Packa, D., Wiwart, M., and Perkowski., J. 2005. Scanning electron microscopy of Fusarium damaged kernels of spring wheat. Int. J. Food Microbiol. 98:113-123.

16. Juge, N., and Svensson, B. 2006. Proteinaceous inhibitors of carbohydrate-active enzymes in cereals: Implication in agriculture. J. Sci. Food Agric. 86:1573-1586.

17. Kasarda, D. D., Dupont, F. M., Vensel, W. H., Altenbach, S. B., Lopez, R. Tanaka, C. K., and Hurkman, W. J. 2008. Surface-associated proteins of wheat starch granules: suitability of wheat starch for celiac patients. J. Agric. Food Chem. 56:10292-10302.

18. Keen, N. T., and Tamaki, S. 1986. Structure of two pectate lyase genes from Erwinia chrysanthemi EC16 and their high-level expression in Escherichia coli. J. Bacteriol. 168:595-606.

19. Koller, A., Washburn, M. P., Lange, B. M., Andon, N. L., Deciu, C., Haynes, P. A., Hays, L., Schieltz, D., Ulaszek, R., Wei, J., Wolters, D., and Yates, J. R. 2002. Proteomic survey of metabolic pathways in rice. Plant Biol. 99:11969-11974.

20. Kuwabara, C., Arakawa, K., and Yoshida, S. 1999. Abscisic acid-induced secretory proteins in suspension-cultured cells of winter wheat. Plant Cell Physiol. 40:184-191

21. Lacey, J., Bateman, G. L., and Mirocha, C. J. 1999. Effects of infection time and moisture on development of ear blight and deoxynivalenol production by Fusarium spp. in wheat. Ann. Appl. Biol. 134:277-283.

22. Lionetti, V., Raiola, A., Camardella, L., Giovane, A., Obel, N., Pauly, M., Favaron, F., Cervone, F., and Bellincampi, D. 2007. Overexpression of pectin methylesterase inhibitors in Arabidopsis restricts fungal infection by Botrytis cinerea. Plant Physiol. 143:1871-1880.

23. Mehta, A., Brasileiro, A. C. M., Souza, D. S. L., Romano, E., Campos, M. A., Grossi-de-Sá, M. F., Silva, M. S., Franco, O. L., Fragoso, R. R., Bevitori, R., and Rocha, T. L. 2008. Plant-pathogen interactions: what is proteomics telling us? FEBS J. 275:3731-3746.

24. Mentewab, A., Rezanoor, H. N., Gosman, N., Worland, A. J., and Nicholson, P. 2000. Chromosomal location of Fusarium head blight resistance genes and analysis of the relationship between resistance to head blight and brown foot rot. Plant Breed. 119:15-20.

25. Miller, S. S., Chabot, D. M. P., Ouellet, T., Harris, L. J., and Fedak, G. 2004. Use of a Fusarium graminearum strain transformed with green fluorescent protein to study infection in wheat (Triticum aestivum). Can. J. Plant Pathol. 26:453-463.

26. Miller, S. S., Yiu, S. H., Fulcher, R. G., and Altosaar, I. 1984. Preliminary evaluation of lectins as fluorescent-probes of seed structure and composition. Food Microstruct. 3:133-139.

27. Paper, J. M., Scott-Craig, J. S., Adhikari, N. D., Cuomo, C. A., and Walton, J. D. 2007. Comparative proteomics of extracellular proteins in vitro and in planta from the pathogenic fungus Fusarium graminearum. Proteomics 7:3171-3183.

28. Pritsch, C., Muehlbauer, G. J., Bushnell, W. R., Somers, D. A., and Vance, C. P. 2000. Fungal development and induction of defense response genes during early infection of wheat spikes by Fusarium graminearum. Mol. Plant-Microbe Interact. 13:159-169.

29. Schwarz, P. B. 2003. Impact of Fusarium head blight on malting and brewing quality of barley. Pages 395-419 in: Fusarium Head Blight of Wheat and Barley. K. J. Leonard and W. R. Bushnell, eds. American Phytopathological Society Press, St. Paul, MN.

30. Skadsen, R. W., and Hohn, T. A. 2004. Use of Fusarium graminearum transformed with $g f p$ to follow infection patterns in barley and Arabidopsis. Physiol. Mol. Plant Pathol. 64:45-53.

31. Stensballe, A., Hald, S., Bauw, G., Blennow, A., and Welinder, K. G. 2008. The amyloplast proteome of potato tuber. FEBS J. 275:1723-1741.

32. Tester, R. F., Karkalas, J., and Qi, X. 2004. Starch-composition, fine structure and architecture. J. Cereal Sci. 39:151-165.

33. Wall, M. L., Wheeler, H., Huebsch, M. P., Smith, J. C., Figeys, D., and Altosaar, I. 2010. The tryptophan rich domain of puroindoline is directly associated with the starch granule surface as judged by tryptic shaving and mass spectrometry. J. Cereal Sci. doi:10.1016/j.jcs.2010.04.002.

34. Zange, B. J., Kang, Z., and Buchenauer, H. 2005. Effect of Folicur in infection process of Fusarium culmorum in wheat spikes. Plant Dis. Prot. 112:52-64.

35. Zhou, W., Eudes, F., and Laroche, A. 2006. Identification of differentially regulated proteins in response to a compatible interaction between the pathogen Fusarium graminearum and its host, Triticum aestivum. Proteomics 6:4599-4609. 